\title{
RADIOCARBON LABORATORY AT THE NATIONAL AUTONOMOUS UNIVERSITY OF MEXICO: FIRST SET OF SAMPLES AND NEW ${ }^{14} \mathrm{C}$ INTERNAL REFERENCE MATERIAL
}

\author{
Laura E Beramendi-Orosco ${ }^{1}$ Galia Gonzalez-Hernandez $\bullet$ Jaime Urrutia-Fucugauchi $\bullet$ \\ Ofelia Morton-Bermea \\ Laboratorio Universitario de Radiocarbono, Instituto de Geofísica, Universidad Nacional Autónoma de México, \\ Ciudad Universitaria, México City 04510, México.
}

\begin{abstract}
This contribution reports the first set of samples and the creation of an internal reference material at the recently opened Radiocarbon Laboratory at the National Autonomous University of Mexico (UNAM). Samples for the initial measurements were selected from archaeological and dating projects on Teotihuacán, one of the largest and best-studied Mesoamerican urban and ceremonial centers. The ${ }^{14} \mathrm{C}$ dates were compared to results obtained by 2 other laboratories in order to assess the results obtained at UNAM and validate the adopted methodology. As part of the quality assurance protocol, an internal reference material was created that consists of charred wood from the Teotihuacán site with a ${ }^{14} \mathrm{C}$ activity in the value range expected for samples from Mesoamerican archaeological sites. Results from 7 analyses have a mean of $1750 \pm 16 \mathrm{BP}$ $(80.43 \pm 0.16 \mathrm{pMC})$.
\end{abstract}

\section{INTRODUCTION}

The Radiocarbon Laboratory at the National Autonomous University of Mexico (UNAM) was created in February 2004. This lab incorporated some of the infrastructure that was part of the dating laboratory at the Institute of Anthropological Research at the same university, which closed in January 2003. The interest and demand for radiocarbon dating have been high since the first dates were reported in the early pioneering studies of Libby and coworkers on the Cuicuilco archaeological site in the Basin of Mexico (Arnold and Libby 1951; Libby 1955). The importance and need for a ${ }^{14} \mathrm{C}$ dating facility in Mexico dedicated to research projects on archaeology, anthropology, and earth sciences have been emphasized a number of times in diverse contexts, but only recently was a university project implemented. Taking into consideration the potential usefulness and role of the newly created laboratory, special attention was given to infrastructure, methodology, accuracy, precision of results, interlaboratory calibration exercises, and the implementation of internal reference material.

The counting system consists of a commercial benzene synthesizer (TASK, Inc.) and a Quantulus $1220^{\mathrm{TM}}$ ultra-low level liquid scintillation spectrometer. During the first year, our activities were focused on the reactivation of the laboratory and its infrastructure, specifically, to the benzene rig dating from the late 1970s, which was unused for some years. The Quantulus 1220, bought in February 2002, was already calibrated for determining ${ }^{14} \mathrm{C}$ before the dating laboratory at the Institute of Anthropological Research closed. The performance of the spectrometer was evaluated, confirming that the stability, background, and counting efficiency were in the manufacturer's recommended value range for the Quantulus 1220.

In order to evaluate the performance of a ${ }^{14} \mathrm{C}$ dating laboratory and detect any analytical problems (sources and magnitude), it is important to perform interlaboratory comparisons as well as regular analysis of standard reference materials (Long 1990). International interlaboratory comparisons are long processes involving several laboratories and different sets of samples, so for a new laboratory it is useful to make intercomparisons with other, well-established ${ }^{14} \mathrm{C}$ laboratories in order to assess the results. As part of the quality assurance protocol, it is also important to analyze reference mate-

\footnotetext{
${ }^{1}$ Corresponding author. Email: laura@geofisica.unam.mx.
} 
rials with certain periodicity (Long 1990; Le Clercq and van der Plicht 1998). There are 8 reference materials available through the IAEA (Le Clercq and van der Plicht 1998); however, the amount available is limited, making it necessary for laboratories to produce their own reference samples that are as similar as possible to the samples routinely analyzed.

We report the first set of dates from 7 samples of known archaeological contexts, checked against duplicates analyzed in 2 other laboratories. We also report on the creation of an internal reference material that will be used as part of the quality assurance program at the UNAM laboratory.

\section{METHODS}

\section{Samples}

The samples for the initial measurements were selected from archaeological projects from one of the largest and most intensely studied archaeological sites in Mesoamerica. Five samples of charred wood were provided from the Teotihuacán Archaeological Project of Dr Linda Manzanilla of the Institute of Anthropological Research, UNAM. Samples were collected in 2003 and 2004 during the excavation of a palace at the Xalla habitational complex, Teotihuacán. Another pair of charred wood samples was obtained from Dr Emily McClung de Tapia of the Institute of Anthropological Research, UNAM. These samples were collected in 1978 from a cave underneath the Pyramid of the Sun at Teotihuacán. A summary of sample provenance and characteristics is given in Table 1.

Table 1 Summary of samples included in the calibration process.

\begin{tabular}{|c|c|c|c|}
\hline Sample code & $\begin{array}{l}\text { Site of collection } \\
\text { and description }\end{array}$ & $\begin{array}{l}\text { Date of } \\
\text { collection }\end{array}$ & Supplier \\
\hline $\begin{array}{l}64547 \\
64908 \\
66799 \\
67418 \\
69668\end{array}$ & $\begin{array}{l}\text { Xalla Teotihuacán, Mexico. } \\
\text { Charred wood from the fall of } \\
\text { ceilings during the final fire of } \\
\text { Teotihuacán. }\end{array}$ & $\begin{array}{l}11 / 2003 \\
11 / 2003 \\
10 / 2004 \\
10 / 2004 \\
11 / 2004\end{array}$ & $\begin{array}{l}\text { Linda Manzanilla } \\
\text { (Inst. of Anthropological } \\
\text { Research, UNAM) }\end{array}$ \\
\hline $\begin{array}{l}\text { TE28C41-5FW } \\
\text { TE28C29-3AE }\end{array}$ & $\begin{array}{l}\text { Pyramid of the Sun, Teotihuacán, } \\
\text { Mexico. Charred wood from an } \\
\text { offering or a fire. }\end{array}$ & $\begin{array}{l}08 / 1978 \\
08 / 1978\end{array}$ & $\begin{array}{l}\text { Emily McClung de Tapia } \\
\text { (Inst. of Anthropological } \\
\text { Research, UNAM) }\end{array}$ \\
\hline
\end{tabular}

Samples were dried at $50{ }^{\circ} \mathrm{C}$ and divided into 2 fractions; one fraction was kept at the UNAM laboratory and the other sent either to the Institut für Bodenkunde, University of Hamburg, Germany, or, by the sample submitter, to Beta Analytic, Florida, USA.

\section{Sample Pretreatment}

Samples were dried at $50{ }^{\circ} \mathrm{C}$, ground, and sieved before inspection under a microscope in order to remove rootlets and other non-sample material. Samples were then washed with distilled water at $40{ }^{\circ} \mathrm{C}$ for $24 \mathrm{hr}$ or until the charred material settled, followed by acid/alkali/acid (AAA) pretreatment. The AAA method consisted of treating samples with $1 \mathrm{M}$ hydrochloric acid $(\mathrm{HCl})$ at $50^{\circ} \mathrm{C}$ for $24 \mathrm{hr}, 0.1 \mathrm{M}$ sodium hydroxide $(\mathrm{NaOH})$ at $50{ }^{\circ} \mathrm{C}$ for $24 \mathrm{hr}$, and $1 \mathrm{M} \mathrm{HCl}$ at $50{ }^{\circ} \mathrm{C}$ for $24 \mathrm{hr}$. Samples were neutralized by washing with distilled water after each acid and alkali wash. Finally, samples were homogenized, dried at $50^{\circ} \mathrm{C}$, and stored in a desiccator until benzene synthesis. 


\section{Benzene Synthesis}

Benzene synthesis was performed in the TASK Benzene Synthesizer via 4 major steps: 1) oxidation, 2) lithium carbide production, 3) acetylene production, and 4) trimerization of acetylene. The reaction conditions were established from the literature (Barker 1953; Tamers 1975; Noakes 1979; Becker-Heidmann et al. 1995), from communication with other laboratories (Randy Culp, CAIS, Georgia, USA; Peter Becker-Heidmann, University of Hamburg, Germany), and from our own experience in order to obtain yields $>90 \%$.

Briefly, $5 \mathrm{~g}$ of sample was combusted in an oxygen-rich atmosphere after the cryogenic removal of water with a trap of dry ice and isopropyl alcohol. The $\mathrm{CO}_{2}$ obtained was trapped cryogenically with liquid nitrogen and sublimed to the storage tanks. The purified $\mathrm{CO}_{2}$ was then pulsed into the reaction chamber to react with an excess of melted lithium metal at $800{ }^{\circ} \mathrm{C}$, yielding lithium carbide $\left(\mathrm{Li}_{2} \mathrm{C}_{2}\right)$. After complete reaction, the $\mathrm{Li}_{2} \mathrm{C}_{2}$ was heated and evacuated for $30 \mathrm{~min}$ in order to remove any radon present in the system. Once the reaction chamber was at room temperature, $\mathrm{Li}_{2} \mathrm{C}_{2}$ reacted with distilled water to produce acetylene $\left(\mathrm{C}_{2} \mathrm{H}_{2}\right)$. The acetylene was purified when passed through a trap cooled with dry ice and isopropyl alcohol and through a tube containing ascarite and phosphorus pentoxide, after which $\mathrm{C}_{2} \mathrm{H}_{2}$ was frozen in a trap with liquid nitrogen. Trimerization was performed using the chromium-activated silica-alumina PKN/D1 catalyst, previously oxidized in a muffle furnace at $450{ }^{\circ} \mathrm{C}$ for more than $24 \mathrm{hr}$ and activated in vacuum at $300{ }^{\circ} \mathrm{C}$ for $24 \mathrm{hr}$. The $\mathrm{C}_{2} \mathrm{H}_{2}$ was slowly passed (while still frozen, with the aid of a trap made of dry ice and isopropyl alcohol) into the catalyst column kept at $\sim 200^{\circ} \mathrm{C}$. Finally, the benzene was removed from the catalyst by applying vacuum, heating to $150{ }^{\circ} \mathrm{C}$, and freezing in a trap cooled by dry ice and isopropyl alcohol.

Benzene synthesis from the oxalic acid II standard reference material (SRM 4990C) was obtained at the same reaction conditions, changing only the oxidation step. Instead of combusting the sample, $18.5 \mathrm{~g}$ of oxalic acid was oxidized with $200 \mathrm{~mL}$ of $6 \%$ potassium permanganate acid solution. Quantities were adjusted to obtain $10 \mathrm{~L}$ of $\mathrm{CO}_{2}$ at room temperature and at Mexico City's atmospheric pressure $(585 \mathrm{mmHg})$. The benzene volume analyzed was $3 \mathrm{~mL}$ plus $0.5 \mathrm{~mL}$ of scintillation cocktail $(0.5 \mathrm{~g}$ of PPO $+0.02 \mathrm{~g}$ of POPOP dissolved in $100 \mathrm{~g}$ of dead spectrophotometric-grade benzene).

\section{Analysis of Benzene Purity}

After the rehabilitation of the benzene synthesizer and determination of the reaction conditions, the purity of the benzene obtained was evaluated. Benzene samples synthesized from oxalic acid SRM4990C and from the charred wood sample 69668 were analyzed by gas chromatography-mass spectrometry (GC/MS) using a gas chromatograph (model 6890, Agilent Technologies) coupled to a mass spectrometer (model 5973N, Agilent Technologies) with an automated injector and a quadrupole mass detector. The GC was fitted with a capillary column (Zebron, $28 \mathrm{~m} \times 0.25 \mathrm{~mm}$ ID, coated with a $0.25-\mu \mathrm{m}$ film of $5 \%$ diphenyl $/ 95 \%$ polidimethylsiloxane). Samples $(0.2 \mu \mathrm{L})$ were injected at $250{ }^{\circ} \mathrm{C}$ in split mode in a $1: 300$ proportion, with $1.2 \mathrm{~mL} / \mathrm{min}$ of helium as carrier gas and at temperatures from $40{ }^{\circ} \mathrm{C}$ (held for $5 \mathrm{~min}$ ) up to $190{ }^{\circ} \mathrm{C}$ by increasing the temperature $10{ }^{\circ} \mathrm{C}$ per min. The transfer line between the GC and the MS was at $280{ }^{\circ} \mathrm{C}$. The mass spectrometer was operated in electron impact mode with a mass range of $\mathrm{m} / \mathrm{z} 35-200$ (2.26 scans per second), with a source and analyzer temperature of 250 and $130{ }^{\circ} \mathrm{C}$, respectively.

\section{Analysis by Liquid Scintillation Spectrometry}

Samples were analyzed using $20-\mathrm{mL}$ and $7-\mathrm{mL}$ low- ${ }^{40} \mathrm{~K}$ glass scintillation vials. First, the geometry of the vials was chosen because the Quantulus 1220 has holders for 20 -mL vials, but since the vol- 
ume of benzene analyzed is $3 \mathrm{~mL}$, the 7-mL vials were considered more appropriate (Pawlyta et al. 1998). Analysis was performed in a Quantulus 1220 ultra-low level liquid scintillation spectrometer. Each sample was analyzed for $2500 \mathrm{~min}$, in 50 cycles of $50 \mathrm{~min}$ each, alternating sample vials with $4990 \mathrm{C}$ standard and background vials. The counting window was set to optimize the figure of merit (FM) with a ${ }^{14} \mathrm{C}$ counting efficiency of $\sim 60 \%$.

\section{Analysis of ${ }^{13} \mathrm{C} /{ }^{12} \mathrm{C}$ Ratio}

Stable ${ }^{13} \mathrm{C}$ isotope analyses were performed by the Stable Isotopes Laboratory at the Institute of Geology, UNAM. Results are reported relative to the Vienna Pee-Dee Belemnite (VPDB) standard with a precision of $\pm 0.2 \%$.

\section{RESULTS AND DISCUSSION}

\section{Benzene Purity}

The partial chromatograms of the total ion current (TIC) for benzene synthesized from SRM 4990C and from the charred wood sample 69668 showed a major peak, comprising more than $95 \%$ of total area, which corresponds to benzene, and other smaller peaks corresponding to other aromatic hydrocarbons. Product identifications and concentrations are given in Table 2.

Table 2 Impurities in benzene samples synthesized from SRM 4990-C and charred wood sample 69668.

\begin{tabular}{lllr}
\hline Sample & Peak & Identification & $\begin{array}{l}\text { Concentration } \\
(\%)\end{array}$ \\
\hline SRM 4990C & 1 & Benzene & 99.05 \\
& 2 & Toluene & 0.95 \\
\hline 69668 & 1 & Benzene & 96.30 \\
& 2 & Toluene & 3.53 \\
& 3 & Ethylbenzene & 0.11 \\
& 4 & Methylethylbenzene & 0.03 \\
& 5 & Methylpropylbenzene & 0.03 \\
\hline
\end{tabular}

Both benzene samples have as impurities aromatic hydrocarbons ranging from toluene to 1-methylpropylbenzene, but the impurities differ in concentration and purity. The benzene sample obtained from SRM 4990C was purer than the benzene sample obtained from the charred wood sample 69668. The reason for this difference is unknown, although it may be due to the different nature of the original sample materials (Switsur and Waterhouse 1989). However, for both samples the benzene purity is $>95 \%$, and these compounds reportedly do not cause quench effects in low concentrations (Becker-Heidmann et al. 1995). These results indicate that the benzene synthesizer is operating correctly and with the proper reaction conditions, resulting in high yields and benzene purity.

\section{Comparison with Other Laboratories}

Two samples (64547 and 64908) were sent to the Institut für Bodenkunde, University of Hamburg, Germany. A comparison of the results is presented in Table 3. Results are in very good agreement: sample 64908 differs by only $60{ }^{14} \mathrm{C}$ yr, while sample 64547 differs by $120{ }^{14} \mathrm{C}$ yr. In both cases, the difference is less than $2 \sigma$. 
Table 3 Results of comparison between UNAM and University of Hamburg.

\begin{tabular}{llll|lll}
\hline & \multicolumn{3}{c|}{ UNAM } & \multicolumn{3}{c}{ Hamburg } \\
\cline { 2 - 7 } $\begin{array}{l}\text { Sample } \\
\text { code }\end{array}$ & Lab code & $\delta^{13} \mathrm{C}$ & $\begin{array}{l}\text { Conventional } \\
\text { age }\end{array}$ & & \multicolumn{3}{c}{$\begin{array}{l}\text { Conventional } \\
\text { age }\end{array}$} \\
\hline 64908 & UNAM-04-01 & -24.13 & $1920 \pm 60$ & HAM-3807 & -23.8 & $1980 \pm 60$ \\
64547 & UNAM-04-04 & n.a. $^{\text {a }}$ & $2160 \pm 50$ & HAM-3804 & -25.1 & $2040 \pm 45$ \\
\hline
\end{tabular}

a Not analyzed.

In a second stage of calibration, 5 samples were sent to Beta Analytic (see Table 4). For 3 samples (67418, 69668, and TE28C41-5FW), the results are in very good agreement, differing by $<40{ }^{14} \mathrm{C}$ yr. For samples 66799 and TE28C29-3AE, the difference is greater, but the results are still in good agreement, differing by 130 and $200{ }^{14} \mathrm{C}$ yr, respectively.

Table 4 Results of comparison between UNAM and Beta Analytic.

\begin{tabular}{llll|lll}
\hline & \multicolumn{3}{c|}{ UNAM } & \multicolumn{3}{c}{ Beta Analytic } \\
\cline { 2 - 7 } & $\begin{array}{l}\text { Lab code } \\
\text { Sample code }\end{array}$ & $\begin{array}{l}\delta^{13} \mathrm{C} \\
(\text { UNAM-) }\end{array}$ & $\begin{array}{l}\text { Conventional } \\
\text { age }\end{array}$ & $\begin{array}{l}\text { Lab code } \\
(\mathrm{BP} \pm 1 \sigma)\end{array}$ & $\begin{array}{l}\delta^{13} \mathrm{C} \\
(\mathrm{Beta})\end{array}$ & $\begin{array}{l}\text { Conventional } \\
\text { age }\end{array}$ \\
\hline 66799 & $05-18$ & -23.87 & $1640 \pm 60$ & 204319 & -23.8 & $1770 \pm 40$ \\
67418 & $05-16$ & -25.48 & $1720 \pm 50$ & 204317 & -24.5 & $1680 \pm 60$ \\
69668 & $05-19$ & -22.61 & $1720 \pm 60$ & 204318 & -22.1 & $1720 \pm 40$ \\
TE28C41-5FW & $05-32$ & n.a. $^{a}$ & $1850 \pm 60$ & 208985 & -24.2 & $1840 \pm 50$ \\
TE28C29-3AE & $05-33$ & n.a. ${ }^{a}$ & $1720 \pm 70$ & 208984 & -24.1 & $1920 \pm 60$ \\
\hline
\end{tabular}

${ }^{\mathrm{a} N o t}$ analyzed.

\section{Internal Reference Material}

A high percentage of the samples that will be analyzed in the laboratory are charred wood from archaeological excavations in Mexico with ${ }^{14} \mathrm{C}$ activities similar to this first set of samples. This makes sample 69668 a possible internal reference material due to its characteristics and abundance $(\sim 500 \mathrm{~g})$.

Results for the 8 different analyses are shown in Table 5 and Figure 1. Separate benzene syntheses were performed for each determination, and an aliquot of the sample, without pretreatment, was analyzed by Beta Analytic as part of the intercomparison. The results are consistent with a mean of $1750 \pm 16 \mathrm{BP}(80.43 \pm 0.16 \mathrm{pMC})$, with only 2 samples falling outside the $\pm 2-\sigma$ error of the mean band: sample UNAM-06-05 by $56{ }^{14} \mathrm{C}$ yr $(0.56 \mathrm{pMC})$ and sample UNAM- $05-20$ by $28{ }^{14} \mathrm{C}$ yr $(0.28$ pMC).

\section{CONCLUSIONS}

From the benzene purity analysis, it can be concluded that the benzene synthesizer has been rehabilitated and is operating properly, producing benzene in high yields and with purity $>95 \%$. The 2 laboratory intercomparisons helped to assess the performance of the counting system at the new UNAM Radiocarbon Laboratory. The results obtained are in very good agreement with results from 2 other laboratories, validating the pretreatment, synthesis, and counting methodology adopted. 
Table 5 Results of measurements for the internal reference material. Result obtained by Beta Analytic for an aliquot of the same sample is shown for comparison.

\begin{tabular}{lll}
\hline Lab code & $\begin{array}{l}\text { Conventional age } \\
\mathrm{BP}( \pm 1 \sigma)\end{array}$ & $\begin{array}{l}\mathrm{pMC} \\
\%( \pm 1 \sigma)\end{array}$ \\
\hline UNAM-05-05 & $1760 \pm 60$ & $80.32 \pm 0.6$ \\
UNAM-05-19 & $1720 \pm 60$ & $80.73 \pm 0.6$ \\
UNAM-05-20 & $1690 \pm 60$ & $81.03 \pm 0.6$ \\
UNAM-05-24 & $1730 \pm 50$ & $80.62 \pm 0.5$ \\
UNAM-06-05 & $1840 \pm 50$ & $79.55 \pm 0.5$ \\
UNAM-06-06 & $1770 \pm 50$ & $80.25 \pm 0.5$ \\
UNAM-06-07 & $1770 \pm 50$ & $80.20 \pm 0.5$ \\
Beta-204318 & $1720 \pm 40$ & $80.73 \pm 0.4$ \\
Mean $^{a}$ & $1750 \pm 16$ & $80.43 \pm 0.16$ \\
\hline
\end{tabular}

a Standard error of the mean calculated as $s e=s d / \sqrt{n} ; n=8$.

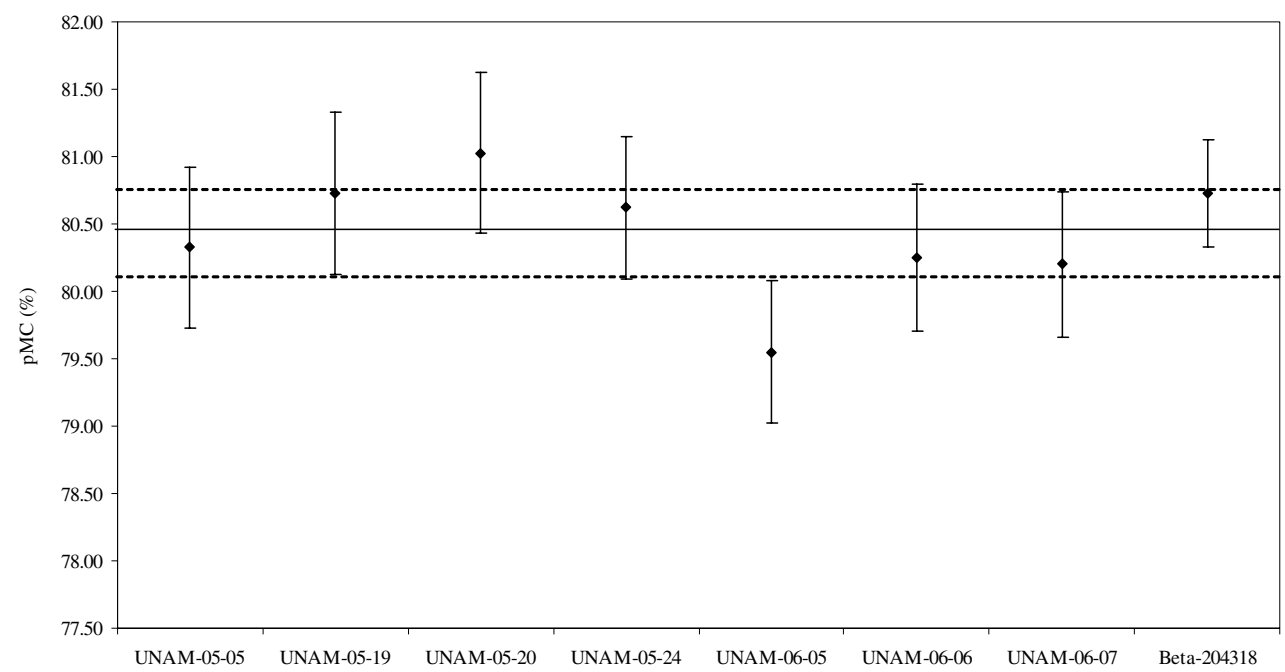

Figure 1 PMC results for the internal reference material obtained for 8 different analyses, including the result obtained by Beta Analytic. Solid line corresponds to the mean and dotted lines correspond to $\pm 2 \sigma$ of the mean.

Sample 69668 can work as an internal reference material, since the results obtained from 8 analyses are consistent, indicating that the sample is homogeneous. This new reference material, with a ${ }^{14} \mathrm{C}$ activity in the value range expected for samples from archaeological sites in Mexico, will help the lab to continuously assess the counting system and methodology and also aid in the early detection of analytical problems.

From the results presented, it can be concluded that the Radiocarbon Laboratory at the National Autonomous University of Mexico is now in operation, with analytical capabilities for generating reliable results. We would thereafter like to present this new lab with the laboratory code UNAM. To further assess the performance of the UNAM Radiocarbon Laboratory, we are currently participating in the Fifth International Radiocarbon Intercomparison (VIRI). 


\section{ACKNOWLEDGMENTS}

The authors thank Peter Becker-Heidmann from the University of Hamburg for helpful advice and dating of samples, and to Linda Manzanilla and Emily McClung de Tapia from the Institute of Anthropological Research, UNAM for providing the samples. Acknowledgement is also due to Pedro Morales and Edith Cienfuegos from the Institute of Geology, UNAM for performing the $\delta^{13} \mathrm{C}$ analyses and to Omar Amador from the Center of Atmospheric Sciences, UNAM for performing the GC/MS analyses. Randy Culp from the CAIS, University of Georgia, provided helpful advice during rehabilitation of the benzene synthesizer. Finally, a postdoctoral fellowship from the Coordination of Scientific Research, UNAM to L Beramendi-Orosco is gratefully acknowledged.

\section{REFERENCES}

Arnold JT, Libby WF. 1951. Radiocarbon dates. Science 113:111-20.

Barker H. 1953. Radiocarbon dating: large-scale preparation of acetylene from organic material. Nature 172(4379):631-2.

Becker-Heidmann P, Hiller A, Hofmann J. 1995. Influence of chromium endowment and surface area of silica-alumina catalysts and of reaction conditions on benzene. Radiocarbon 37(2):717-25.

Le Clercq M, van der Plicht J. 1998. New reference materials with activities of 15 and 50 pMC. Radiocarbon 40(1):295-7.

Libby WF. 1955. Radiocarbon Dating. 2nd edition. Chicago: Chicago University Press. 175 p.
Long A. 1990. A quality assurance protocol for radiocarbon dating laboratories. Radiocarbon 32(3):393-7.

Noakes JE. 1979. TASK Benzene Synthesizer. User's Manual. Athens, Georgia, USA.

Pawlyta J, Pazdur A, Rakowski AZ. 1998. Commissioning of a Quantulus $1220^{\mathrm{TM}}$ liquid scintillation beta spectrometer for measuring ${ }^{14} \mathrm{C}$ and ${ }^{3} \mathrm{H}$ at natural abundance. Radiocarbon 40(1):201-9.

Switsur R, Waterhouse JS. 1989. Benzene purity in radiocarbon dating samples. Radiocarbon 31(3):260-3.

Tamers MA. 1975. Chemical yield optimization of the benzene synthesis for radiocarbon dating. International Journal of Applied Radiation and Isotopes 26: 676-82. 